\title{
Searching for the Holy Grail: The Evolution of USAID Legislative Support Programming
}

\author{
Edward R. McMahon
}

Department of Community Development and Applied Economics, University of Vermont, USA

Copyright $\bigcirc 2017$ by authors, all rights reserved. Authors agree that this article remains permanently open access under the terms of the Creative Commons Attribution License 4.0 International License

\begin{abstract}
Over the past three decades the U.S. Agency for International Development (USAID) has undertaken programming designed to support legislatures in playing their role as an integral part of democratic governance. The particular areas of emphasis in programming have evolved due to experience gained, shifting policy priorities, and changes in resource levels. The parabola of assistance arcs from a) basic legislative technical and material assistance to b) an emphasis on legislative modernization plans and champions to c) a broader-based legislative "engagement" approach linking legislative support activities with cross-sectoral policy development and implementation. The latter approach is designed to foster economic and social development. We explore the reasons for this evolution and posit that there has been a move in the direction of USAID programming to support activities to promote integrated and broader development goals. We suggest that there are problems and challenges related to this approach; legislative engagement is not necessarily the alpha and omega of legislative functioning. We conclude however, that despite these challenges, ignoring the interface between legislative support and development may negatively impact the attainment of developmental goals and marginalize legislative support as a subject worthy of USAID focus.
\end{abstract}

Keywords Democracy, Foreign Aid, Legislature

\section{Introduction ${ }^{1}$}

In the past decade, partly as a result of the impact of the Millennium and Sustainable Development Goals, there has been increased recognition of the inter-related nature of key areas of social development. To cite just a few examples, agriculture impacts food security; climate change impacts

1 Research Funding for a previous version of this paper was provided by the USAID Center of Excellence for Democracy, Human Rights and Governance. health, and democratic governance impacts most developmental sectors. One aspect of governance, representative legislative institutions, is a factor in nascent democracies around the world from Indonesia to Tunisia to Colombia. Legislatures constitute a central point in the developmental equation, as they play a role in determining budget levels, resource allocation, policy directions, and implementation of developmental goals. A lack of institutional governance structures such as functional legislatures will negatively impact a range of developmental goals. This factor, and initiatives undertaken by the international community to support legislatures to play their role in development, has received insufficient attention in academic and policy communities.

In recent years there has been an identifiable evolution of donor-funded legislative support programming from mainly legislative strengthening, which has emphasized technical and material assistance to legislatures, to encompass a more cross-sectoral, integrated legislative engagement concept. This is designed to work with other thematic areas such as health, education, economic growth or the environment to achieve policy goals through legislative action. While this evolution is common to a number of donor agencies, it is especially emphasized in US Agency for International Development (USAID) programming.

This article examines and assesses the evolution of USAID's legislative support programming. We are interested in the choices USAID has made in seeking to help empower legislatures to play their role in democratic governance, and whether these represent a consistent and evolving strategy, or have been primarily reactive in nature. This evolution has taken place against a backdrop of increased pressure on donor democracy assistance budgets in general, and questions about the impact and utility of legislative support programming in general.

Given the limited amount of empirical data on this subject, the methodology utilized here has been document review, key informant interviews, and the use of two case studies. We first identify key themes in the literature. We then review the various phases of USAID's legislative support activities. We examine the range of activities designed to support the 
development of legislatures. We consider legislative strengthening and modernization, including the ways in which legislative engagement programming relates to USAID development goals in other sectors (e.g. health, agriculture, environment, economic development), and the strategies deemed most effective in achieving these goals. The last section presents generally positive conclusions relating to legislative engagement programming, while also identifying complicating factors and challenges suggesting that USAID's search for the Holy Grail of effective legislative support programming is likely to continue.

\section{Legislative Support Programming: Evolving From Strengthening to Modernization to Engagement}

The existence of a strong legislature is essential for a transparent and accountable policy-making process. Without it the executive can unilaterally make and implement policies with any sort of check or balance, which can negatively impact development priorities. Examples of poor management of state resources in authoritarian developing world contexts have abounded. In a functioning democracy, however, legislatures are entrusted with "the responsibility to make sure that a state spends money well and wisely, that it delivers good and appropriate policy, and that it steers the nation admirably and surely" [1] Arter [2] emphasizes that legislatures need not only sufficient capacity and operational functionality but also the political will and ability to utilize the first two prerequisites to actually carry out their responsibilities. Other scholars of legislative functioning stress the need for openness and visibility of legislative actions. For example, Malesky et al [3] note "evidence that politicians respond to greater transparency with better performance. Better access to information seems to force politicians to respond more appropriately to citizen demands, both in developed and developing countries."

The ability of the legislature to contribute to broader developmental objectives is also a key test of its role and relevance. Kroenig and Karan-Delhaye [4] consider whether stronger legislatures lead to the adoption of laws and programs that increase economic growth and reduce poverty. They suggest that "countries with more powerful national legislatures not only possess higher levels of economic growth, but they also enjoy higher levels of human development and lower levels of income inequality". The authors conclude that legislatures have an important role to play in determining the macro-economic course of a country's economic development and that strengthening national legislatures should be an urgent priority for governments and donors focused on improving standards of living in the developing world. Sharkey [5] takes a somewhat more overtly advocacy-oriented approach, emphasizing the role that national legislatures can play in promoting poverty reduction strategies. They observe that the involvement of legislatures can promote national "buy-in" for donor efforts to promote economic development and that in doing so legislatures can also provide perspectives that would not have otherwise been heard, in a process often dominated by donors and the executive branch.

The governance environment must be well understood before engaging in project interventions. Without a thorough understanding of this context, feasible options cannot be identified nor can they be pursued in a fashion ensuring a high success rate. Cornell [6] examines, for example, whether the effect of democracy aid differs between different types of authoritarian regimes and concludes that such aid's impact is indeed related to the nature of the authoritarian government. As Barkan [7] argued in a seminal project focusing on African legislatures, the government's relationship with the public, the strength of political parties, and the significance of the electoral system are all aspects that play a key role in determining the effectiveness of legislative strengthening and development.

Rugumamu [8] echoes these lessons, emphasizing the need "to strategically link the democracy support, peace, and development issues in order to comprehensively address the structural root causes and consequences of fragility." While Rugumamu points out the potential to achieve enhanced results by addressing both legislative strengthening and the sources of state fragility, the process of nurturing a strong legislature in the context of a weak state presents many challenges. Special attention, for example, must be given to determining which legislatures are most likely to benefit from donor assistance. While the ultimate goal may be legislative strengthening, legislatures in developing countries face some fundamental cleavages and challenges, including a lack of resources and knowledge, which may constrain efforts to achieve realistic and attainable results.

Since the advent of democracy and governance programming, bilateral donors such as USAID have included support for legislative development as an important component. This programming has been based on the belief that nascent democracies need to build legislatures strong enough to act not only as checks on executive power, usually in contexts in which the executive has been long dominant, but also as independent and influential actors in their own right, including exercising representation and law-making functions.

\subsection{Legislative Support Programming}

USAID has undertaken dozens of projects designed to support the various facets of legislative development. This approach has resulted in some successes but it has also generated questions about its effectiveness and sustainability. As USAID has gained more experience in this field, and budgetary constraints have increasingly become a reality, USAID's emphasis has tended, in general terms, to evolve from assistance focused on internal, technical aspects of the functioning of the legislature to the generation of support 
within legislatures for reform, and currently integrated programming with other USAID developmental goals and sectors. For definitional purposes, we refer to the first phase as legislative strengthening work, the second as legislative modernization and the third as legislative engagement.

These three categories overlap chronologically. Neither are they exclusive; legislative strengthening and modernization activities continue. They are, however, generally valid helpful and credible conceptual yardsticks of the evolution of legislative programming. We are interested in identifying the elements of these different areas of focus, and the reasons for why these shifts have occurred. This can advance the state of the art and inform our understanding of the overall effectiveness of legislatively-oriented programming; for example, were these shifts a result of a lack of success of the previous phase, or do they build on past successes?

\subsection{Legislative Strengthening}

With the global advance of democratic reform in the last third of the $20^{\text {th }}$ century donors began to make significant efforts to strengthen legislatures, which were often the "poor cousins" to the executive in terms of the exercise of power The first wave of legislative support programming was initiated in the mid-1980s. It was oriented towards the provision of "nuts-and-bolts" basic-type assistance regarding legislative functioning, with the expectation that providing legislatures with the tools and information regarding the legislative process would by itself result in stronger legislatures. Legislative strengthening efforts have fallen into two distinct categories; the first comprises technical assistance regarding legislative processes, including areas such as constituency building, committee support, and legislative drafting. The second consists of hardware and durable goods that are utilized by legislators and staff in the pursuit of their duties. These may be communications and other materials and equipment as well as information technology materials and support.

Programming began in Central America, as the USG sought to support the advent of democratic institutions as that region emerged from years of crisis in the 1970s and 1980s. For example, a regional legislative support program was initiated in 1985; at the same time a project specifically targeted for El Salvador was initiated. The mandate for the former was to provide "Training on developing and improving legislative procedures in Central American parliaments; technical assistance, training and study tours for MPs to the United States and other democratic countries", while the latter's was to "Strengthen the Legislative Assembly's capacity to engage in more informative and analytical policy dialogue; enhance the operational effectiveness of the Legislative Assembly through the provision of technical assistance, training, equipment and study tours".

Similar legislative strengthening programming blossomed in central and eastern Europe after the fall of the Berlin Wall and the dissolution of Soviet-style authoritarianism. The "Gift of Democracy to Poland" was authorized by Concurrent Resolution by the U.S. Congress in 1989, and it was followed by establishment of a Speaker's Task Force initially chaired by Representative Martin Frost of Texas, which expanded technical assistance efforts to other central and eastern European legislatures. This assistance was focused primarily on the provision of durable goods such as computers, other hardware such as electronic voting tally machines, and information on legislative procedures and processes. Other Congressionally supported legislative support programming initiatives in the early years were directed through the semi-independent National Endowment for Democracy.

As this assistance was precedential, and in many cases the legislatures being assisted were functioning in a democratic environment for the first time, there was a paucity of benchmarks by which its impact could be measured in any rigorous fashion. Few post-project evaluations appear to exist. What information was available presented mixed results. For example, the impact of assistance through the Gift of Democracy program was judged, in at least one major study, to be "surprisingly modest" [9]. Another perspective, however, articulated by a senior Polish parliamentary source, was that the project provided "very significant help" [10].

We find numerous references in the literature to a number of elements that have been a focus of USAID's legislative strengthening efforts. The strengthening of committees has been perceived as essential to the overall functioning and power of the legislature. Much of the nuts and bolts of legislative work take place in committees, and poorly structured or weak committees and/or insufficient and inadequately trained staff members will hamper the conduct of legislative duties. Bryan and Hoffman [11] noted the weakness of legislatures in several developing African nations, stating, "Committee appointment systems that do not take legislators' backgrounds into full account also miss opportunities to build on existing capacity in specific areas." Barkan [12], in his study of African legislatures, suggests that a universally accepted principle found in more consolidated democratic legislatures, that a well-developed system of parliamentary committees conducts oversight for government ministries, departments and agencies is essential for legislatures to perform their defining functions. Equipped with ample members and plentiful education and expertise, committees can be potent sources of knowledge and support. 
Table 1. Evolution of Legislative Support Activities

\begin{tabular}{|c|c|c|}
\hline \multicolumn{3}{|c|}{ Legislative Support Activities (dates are approximate) } \\
\hline $\begin{array}{c}\text { 1985-2000: Legislative strengthening - Core } \\
\text { legislative functioning and training, material } \\
\text { good provision. }\end{array}$ & $\begin{array}{c}\text { 1995-2010: Legislative modernization - } \\
\text { Identification of and support for agents of } \\
\text { change within legislatures. }\end{array}$ & $\begin{array}{c}\text { 2010-Present: Legislative engagement - } \\
\text { Identification and promotion of development } \\
\text { policy issues within legislative context. }\end{array}$ \\
\hline
\end{tabular}

The legislative research function has received considerable programmatic emphasis. Arter [13] emphasizes that a necessary requirement for legislative effectiveness and legislative autonomy is that the legislature can acquire the information it needs to examine government measures without need to depend on information to do so supplied by executive sources. The goal has been to provide legislators and staff with access to the knowledge and information necessary for informed public policy decision making. A report by the Inter-Parliamentary Union [14] highlighted the importance of administrative and research staff having access to credible and policy-relevant information. Datta and Jones [15] note that "Legislatures can improve their research literacy and promote better understanding of their research needs through enhanced networks and joint working with researchers as well as with legislators from other countries." Recommended methods have included seminars, exposure to effective research approaches undertaken in other legislatures, public hearings, and the creation of effective research facilities. Cuninghame [16] emphasizes the potential of well-functioning libraries.

Information technology and technical support present seemingly advanced methods for many developing countries, but small changes lead to positive results in some cases. Regarding a project in Timor Leste, for example, a Democracy House Partnership report Dreier [17] cites refined software capabilities leading to "greatly improved internet and network connectivity for members of Parliament and the parliamentary research service improving their ability to use the library to undertake legislative research and analysis." The Inter-Parliamentary Union [18] suggests that "by adopting new methods and technologies in information management, these services can provide part of the solution to information overload and to issues of legislative quality and accountability."

Legislative drafting has also been viewed as a key element of the legislative function. In discussing the Ugandan parliament, Andrews and Bategeka [19] identify dialogue, analysis, and scrutiny as essential steps before even beginning the drafting process. It is crucial that the technical side of writing bills is understood, as "this process begins with brainstorming about the entry points for reform." Roth [20] further elaborates on the importance of competent and well-informed participants in the legislative drafting process, noting "Where legislation is initiated by MPs, expert advice is even more important and will certainly need to include advice on drafting." In order to create effective legislation, the components of infrastructure and support should be in place to ensure that the process can be carried out successfully and knowledgably.
Improving the ability of legislatures to effectively manage the budget process is an increasing focus of legislative support efforts by donors. The empowerment of legislatures to effectively engage in this function can also prevent corruption and ensure that money is being allocated to the issues of greatest import. Past outcomes demonstrate that the alignment of internal interests and external aid is critical. Purcell et al [21] present a situation in "Evaluation of General Budget Support-Uganda" in which expressed donor interest in budget reforms mirrored that of parliament, but unfortunately the government seized on this to complain of foreign interference and ignored the fact that the parliament had similar views. Thus, communication is necessary not only between constituents and the government but also among other reform actors and the government.

The budget process impacts economic development. Wehner [22] suggests that "The budget is the key economic policy tool of the government, and constitutes arguably its most comprehensive statement of priorities." Channeling reform efforts to legislative strengthening can create a better budget process and in turn increase the prospective for economic progress. The annual budget process is embedded within a broader socio-economic and political environment that affects the potential for legislative scrutiny. Thus, the repercussions of a strong budget process are far-ranging. McKie and van de Walle [23] state that "the manner in which budget execution is undertaken impacts development in a country in terms of the effect it has on the quality of physical infrastructure that is built, the availability of crucial social services, and the efficiency of government entities to facilitate economic advancement."

Johnson and Stapenhurst [24] identify the use of nonpartisan budget offices as another potential strategy, which can isolate the development of economic assumptions and budget issues from political influence. Staddon [25] elaborates the importance of oversight and the role of the Public Accounts Committees in Trinidad and Tobago and Jamaica, "responsible for the non-partisan audit of public expenditure and control of the public purse." These PACs possess the authority to consider issues of efficiency and economy of program implementation. The ability of nonpartisan teams to conduct their own research and provide independent information potentially enhances functioning and serves to check the activities of the executive in their involvement in this process. The involvement of civil society in the budget process can also be very helpful.

In the wake of experience in what, after all, was a new area of activity, USAID began to gain some expertise. One observation emerged that while technical assistance in the form of legislative strengthening could be helpful to nascent 
legislatures, legislatures needed to be open to assistance. This in turn should be put in the context of a broader strategy articulated and embraced by the legislative leadership itself. In the absence of this, assistance risked being ephemeral and non-sustainable. It was not sufficient to do information and hardware "drops" in nascent legislatures; such efforts could be wasted if there was not a receptive environment and a sustained commitment to improvement on the part of the recipient legislature. In a critique of a legislative strengthening programming, for example, Carothers [26] noted:

The training sessions for legislative staff do not deal with the facts that the trainees are beholden to powerful political bosses and are not given much of a role. Shiny new computers sit unused on legislators' desks or disappear. New parliamentary committees are formed at the urging of outside advisers but end up as fiefdoms of the senior legislators who are the root cause of the parliament's poor performance.

In addition, donors found that the amount of turn-over of members of parliaments through competitive elections contributed to a sustainability problem. Dealing with legislatures involved different dynamics than with working with executive branches or civil society. Victory was thus not declared by donors in the legislative support arena; rather thinking evolved as to how legislative support could be more effectively delivered.

\subsection{Legislative Modernization}

In light of the identified limitations of legislative strengthening, by the late 1990s more legislative projects began to focus on or at least include an emphasis on the concept of legislative "modernization". This refers to projects designed to identify and encourage the development of a core of support amongst influential legislators and staff interested in reforming and improving legislative functioning, who could serve as key interlocutors over time. Projects began to include specifically targeted assistance to legislative committees interested in modernization.

The theory behind the legislative modernization approach was two-fold. First, the identification of influential supporters, or "champions" of modernization could help legitimize external efforts and provide a committed core of legislators and staffers to take ownership of initiatives to strengthen legislatures over an extended period, thereby responding to the emphasis on sustainability that had become a central element of many donor programs. Second, the approach called for, when possible, the development of institutional and policy roadmaps designed to mainstream modernization efforts within the legislature. Thus, the concepts of modernization committees and modernization plans gained currency. In substance, however, the heart of modernization efforts remained focused on legislative strengthening tactics and tools. A central component of modernization thus included significant technical assistance and staff training for capacity-building. Some illustrative examples included:

- Guatemala Congressional Modernization (1997). USAID's provided technical assistance to the Guatemalan Congress as part of the second stage of its Master Plan for Legislative Modernization.

- Colombian Congress Strengthening Program (2002). Support for the creation of the Modernization Commission formed by representatives of the Congress in charge of implementing the Modernization Plan.

- Iraq and Jordan Legislative Support Projects (2005). These projects had a mandate to modernize legislative processes.

Experience with the modernization approach was mixed. Several evaluations suggest positive results from such programming. For example, the Ukrainian legislature, the Verkhovna Rada, was the subject of sustained USAID-funded programming in the early 2000's. One assessment determined that this effort contributed to its functioning due to "the huge increase in staffing, the expansion in the number of Rada offices and buildings, the larger parliamentary budgets, and the greater utilization of computerization and information technologies" [27]. A review of a project in Jordan highlighted similar activities to establish a legislative resource training center and a budget office [28]. With the support of legislative leaderships these assistance efforts contributed to providing a foundation for strengthened legislatures.

There was also, however, evidence suggesting that the modernization approach might not be a panacea. Legislative member turnover complicated efforts to create sustainability. The extent of members' commitments to modernization was invariably impacted by political or other contextual considerations. Carothers [29] has suggested that "by far the biggest obstacle is the paucity of interest in reform among the main power-holders in the legislatures of many transitional countries." In some cases, a sense of entitlement or a lack of motivation rendered legislators passive regarding sustained leadership in modernization efforts.

This lack of buy-in is reflected in a number of USAID project evaluations. One such study observed that, "The greatest challenge was the lack of concrete support and participation by the Congress, with a few exceptions, in OTI's efforts to collaborate on a reform process" [30]. Similar results were noted in a USAID Nigerian project: "There was a lack of buy-in on the part of the political leadership of these beneficiary institutions/organizations. Where this occurred, there was a disconnect between the needs (as perceived by the implementing partners) and what the leadership of the beneficiary institution considered its wants" [31]. A 2013 evaluation of a USAID funded legislative modernization project in Liberia stated that "Legislators were uniformly candid in admitting that the Legislature's commitment to modernization-and thus to the program-has been limited and that they have not fully benefitted from the program" [32]. An evaluation of 
legislative support programming in Iraq notes, "Those programs whose primary focus has been on institutions building - strengthening the capacities of the legislative and executive branches of the transitional governments, and assistance to the constitutional drafting process-have not achieved their long term results" [33].

Thus, although aspects of modernization in a number of projects may have endured, the extent to which this approach by itself has resulted in lasting contributions to legislative functioning is an open question. Modernization requires finding champions - those who want to strengthen the legislature for solely the legislature's sake. However, such individuals are limited in number as legislators' paramount concern is often continuity in office. The implementation of projects whose primary focus is simply strengthening the legislature has proven questionable. Lack of buy-in from legislative leadership, along with the cost and challenges in terms of identifying credible indicators contributed to donor fatigue on these types of projects. In addition, the issue of corruption is widely seen as central to the problem. Finally, political parties are at the same time too strong and too weak to play a constructive role, as they often have dominant top-down leadership structures, and lack the internal capacity for policy review and consideration of options.

\subsection{Legislative Engagement Programming (LEP)}

In the wake of USAID's experience with the approaches cited above, legislative support programming assistance has evolved in recent years to include more emphasis on integrated, cross-sectoral project design e.g. projects with potential for meeting multiple developmental goals. Poverty reduction has proven to be one of the most common cross-cutting issues. Strong institutions and parliaments already in place can greatly help to sustain efforts to combat poverty, while weak countries with low functioning legislatures often face the most formidable poverty problems [34]. In this context the involvement of civil society is an especially influential factor for both cross-sectoral missions and the enhancement of democracy and governance [35]. The UK Department for International Development has also placed significant emphasis on the relationship of legislative strengthening and poverty reduction [36].

Legislatures can play a significant role in promoting accountability and transparency in achieving sustainable development goals. The UNDP Manual for Parliamentary Engagement Development with the Millennium Goals [37], for example, outlines the importance of legislatures in implementing these goals and the practices through which action can be taken, effectively encompassing the general rationale for legislative engagement programming. Combatting poverty entails diverse approaches, including the development of institutions to give citizens the necessary resources for involvement, education to ensure that citizens have an understanding of the political processes, and the creation of an environment in which legislatures are both willing and able to listen to their constituents' needs. In order to make lasting change there must exist the means through which new policies can be executed. Kroon and Stapenhurst [38] emphasize the challenge of poverty reduction in highlighting the legislature's unique ability to embody the needs of the citizens through analysis, implementation, and evaluation of the policy process.

Economic development is a logical sequel to poverty concerns. Sharkey et al [39] highlights the role that national legislatures can play both in both promoting poverty reduction strategies and encouraging national "buy-in" to the donor efforts to stimulate economic development. Not only can legislative actions contribute to promoting widespread support for economic reform, but greater involvement of the legislature may also provide invaluable insight and a second look at the actions of the executive in determining the path of economic growth. Generally, strong political institutions lead to stronger economic institutions; as the importance of the legislature is acknowledged by Kroenig and Karan-Delhaye [40]: "Without secure property rights and access to economic resources, individuals will lack the ability and the incentives to invest in the economy and to participate in economic activity." Thus economic growth may not be merely a cross-cutting option but an essential factor for the success of reform.

In the natural resource sector, Lippman [41] identified positive program results linking environmental issues to democracy. 2 While problems of corruption and implementation methods persist, there are several generally agreed upon targets for environmental reform. In the case of the Philippines, Lippman [42] stated that "The environment was a natural setting for cross-sectoral linkages because it combined the mission's local governance and natural resources management programs with the government's commitment to decentralization and concern about the environment." The legislature is constantly cited as a key to mitigating corruption in the area of natural resource extraction through increased transparency. Legislative support can potentially play a key role in capacity building to obtain information and exercise accountability in order to mitigate excessive corruption. Bryan and Hoffman [43] emphasize that in many resource-rich countries in Africa the lack of accountability and transparency in the management of natural resources has fueled cycles of corruption, conflict, and poverty. They note that a growing number of African legislatures have passed laws intended to ensure the sustainable and accountable management of their countries' natural resources. The linkage of legislative and cross-sectoral programs is therefore essential, as the key to addressing environmental conflicts in many cases is through the development of effective governance institutions, the passage and implementation of appropriate legislation, and increases in operational transparency. Cross-cutting work in

2 Lippman's precedential work identified the concept of cross-sectoral, legislative engagement programming long before it became prevalent. 
other sectors such as health and education may also allow the government to play a larger role in effectively carrying out the implementation of services and allocation of resources.

Cross-sectoral development programming is, therefore, an area of increased focus, comprised of several unique components linking democracy and governance to other sectors of reform. Its importance has been emphasized in the current era of limited resources for development and greater recognition of governance as the key to promoting other developmental goals [44]. This is due in part to the growth of initiatives such as Feed the Future, Power Africa and PEPFAR, and other poverty reduction, economic growth and disaster risk management initiatives. ${ }^{3}$ It is also a result of a confluence of factors including a) a reaction to challenges encountered in the legislative strengthening and modernization approaches; $\mathrm{b}$ ) increased understanding of what is needed to heighten the effectiveness of legislatures; and c) the realities of an increasingly constrained funding environment in which USAID is required to achieve more with fewer resources. The shifting of funding away from democracy and governance activities into other sectors has resulted, in some cases, in more innovative and integrated project designs reflecting heightened recognition that legislative buy-in can be a critical element in promoting development initiatives. ${ }^{4}$ Conversely, the absence of such involvement can stymie, retard or otherwise impede development initiatives.

A key question for this legislative engagement approach has been how to most effectively operationalize it. Is there a primary programmatic "vehicle" for programming which could positively impact a legislature's ability to contribute to economic and social development goals? While apparently not based on any formal USAID decision, the weight of evidence points towards particular emphasis on the articulation and promotion of policy alternatives that can impact progress in other developmental sectors. Legislative engagement programming reflects a need to promote "an informed legislative community" (e.g., civil society, constituencies, research institutes) to both advocate for policies and to serve as an information resource for the legislatures, to help strengthen their engagement and input into policy development.

USAID has hypothesized that this could result in legislators engaging in more pro-active dialogue with constituents and stakeholders on a variety of specific development issues, thus feeding additional and more regularized flow of information into the legislative process.

3 The role of legislatures on the revenue side of the budget - setting tax rates and other government income - has received relatively less attention in legislative support programming, but this may change with increased attention to domestic resource mobilization as a key to sustainable development.

4 Another result of the more constrained funding environment has been the subsuming of legislative support activities with other $\mathrm{D} / \mathrm{G}$ programming emphasizing the diffusion of power away from highly centralized executive authority, such as municipal governance (e.g. Colombia) or broader decentralization efforts (e.g. Bolivia).
The growing number of recent legislative engagement project designs reflect this determination that the most appropriate vehicle is that of influencing the policy debate, providing informed data and information, and shaping the culture of information flow for legislators to use and guide their decisions, which include not only the development and passage of legislation itself but also amendments, oversight, regulations, and other relevant actions.

This approach can be divided into two main areas of focus. The first is the development of empirically driven research and information generation to contribute to an informed policy-making process. This can flow from research capacities within the legislature itself, civic and advocacy organizations, non-partisan research initiatives and/or university-based bodies. Experience suggests, however, that it is not sufficient to create the basis for sound policy decision making; the legislature must be aware of and empowered and willing to use it. Policies must also be effectively implemented, which usually requires the cooperation of the executive. Thus, the second focus area includes the processes and modalities by which this information can be fed into the legislative (and executive) branch(es), and how perspectives between these two branches can be mediated and synthesized, in the best of circumstances, to produce effective governmental policies and positive developmental outcomes. The provision of technical assistance on advocacy efforts has long been an element of demand-side legislative support programming, in which the capacity of non-governmental stakeholders to articulate their needs with executive and legislative branches is enhanced. Unlike past activities, however, legislative engagement programming integrally links generic advocacy capacity building with specific issue areas.

In order to be successful, there must be focus on policy issues that generate interest from legislatures. Thus, legislative engagement seeks to strategically involve and partner with members of parliament. Legislative engagement work can generate results in the specific sectors in which the programs are carried out. To cite one example, a report on USAID's approach to addressing disability issues noted the significant effects of linking reform to policy issues, stating, "These reports [on impact of efforts to meet the Action Plan objectives] are closely read by the disability community and have influenced congressional interest and legislation [45]. The programs have taken place throughout Africa, Asia, the Middle East, and Latin America and have seen impressive results, such as the combining of efforts with the Armenian Legislative Strengthening Program and new legislation to assist people with disabilities in countries such as Bosnia-Herzegovina and Georgia.

Another example of the legislative engagement approach has been the Consortium on Political Processes (CEPPS) Natural Resource Management Strengthening Program in Niger. The evaluation of this project noted the "free reign [over natural resources] that successive authoritarian governments and foreign mining companies enjoyed for most of the country's history creates a problem that is only 
likely to be solved through working both directly for this issue, while dually addressing the governance issues involved" [46]. This led the implementing organizations to develop policy objectives focused on legislative strengthening through capacity building and collaboration with civil society, as well as the key goal of addressing natural resource management, respectively. Efforts channeled at reforming legislative practices had a specific policy end goal of improved oversight of the mining sector [47].

Carothers [48] provides an insightful articulation of what has come to, in part, underlie the legislative engagement approach:

The point is not that weak, troubled legislatures can never change. It is, rather, that treating legislatures as self-contained entities that can be fixed by repairing internal mechanisms is unlikely to get very far. Rather than seeing the task as legislative assistance per se, it is more useful to think in terms of helping a society develop the capacity to enact laws that incorporate citizens' interests and reflect sophisticated knowledge of the policy landscape. Ultimately, helping bolster this capacity will mean working with many people and groups outside the legislature, including political parties, citizens groups, the media, officials from the executive branch, jurists, and others.

\section{What Have We Learned From LEP}

Development goals such as health, education and agriculture often require supporting public policy initiatives. These, while generally developed by the executive, usually often require legislative input and approval. Despite this, while the state of the art of USAID legislative support programming continues to evolve, and there is a strong rationale for a move towards more integrated programming, its long-term impact is not yet clear. The following are some key themes that emerge from consideration of the evolution of legislative support programming.

\subsection{Conditions Favoring Policy-Oriented Legislative Engagement Programming}

To enhance the potential for success of a LEP project, there should be a convergence of several elements. First, USAID priorities should include issues that call for policy initiatives for reform. Second, civil society organizations should be interested in and focused on the same issues. Third, there should be some level of willingness on the part of at least some elements in the legislature, and also probably the executive branch, to receive input on these issues from civil society and the broader population as well. The reality is that these elements probably won't all need to be present, especially in the same magnitude at the beginning, but a successful project may result in their coming together.

\subsection{LEP Plus}

A fundamental question associated with LEP programming is whether the evolution of legislative programming has been strategic and sequential, or whether is represents a scattershot, experimental approach to seeking results. The reality, in fact, appears to be mixed. Legislative support programming has been evolutionary and a learning process, but without each phase having been "completed", as a pre-requisite to the next. Legislating is far too complex and challenging an endeavor to expect that there could be a cut-and-dried simple sequential approach. Legislatures change, MPs turn-over, issues evolve, political contexts change and resource levels vary. This reality means that even if emphasis on legislative engagement programming integrated with other sectors is deemed to be advisable, there may also well be an ongoing need for emphasis on traditional legislative strengthening approach. A dysfunctional legislature can torpedo the best of policy initiatives. In addition, legislators often value attention paid to the legislature for reasons more than simply the passage of a particular policy initiative. Thus, if legislative engagement with other sectors simply consists of facilitating the passage of specifically desired legislation without reference to the internal dynamics of the legislature, the approach may well fail to meet some or all of its objectives. So there must be some continuing focus on the mechanics of the legislative functioning and process.

A prospective way of dealing with this would be what could be considered a "legislative engagement plus" strategy. This would mean the main project focus is on policy development processes, but that this should be accompanied by some ability to undertake legislative strengthening activities. Simply taking a purely sectoral (e.g., health, education, environment) approach may not be sufficient. The legislature needs to be empowered to do its work. There are often structural problems in terms of legislative functioning that can impede the efficacy of the policy-making process. Moreover, members of legislatures want to see tangible benefits from programming for the legislature and themselves; they do not like simply being used as the means to an end of a desired policy output. Dealing with the legislature must involve building up trusting relationships and support for legislative capacity development; providing support for specific legislative initiatives from other sectors is not likely to be a productive approach unless there is some sort of legislative capacity-building element to the project. In addition, with simply an LEP approach, democracy and good governance promotion risks losing its intrinsic value and may simply become an appendage of other developmental sectors. They may be inclined to, for example, simply strive to see a particular piece of legislation passed quickly, but with no structured and longer-term legislative capacity-building element. 


\subsection{LEP has been Largely DRG-Inspired}

To date legislative engagement activities have been largely undertaken by the Democracy, Rights and Governance (DRG) unit within USAID, rather than the other USAID development sectors. DRG has been, in essence, the supplicant for other sectors to become involved. The extent to which this means that other sectors are a) not engaging in legislatures on policy dialogue, or b) are doing it but not in coordination or cooperation with DRG is not clear. Anecdotal evidence suggests that the former explanation may be more prevalent than the latter. In any case, there appears to be a significant need for DRG to sensitize and educate other sectors about the importance of working with DRG on LEP initiatives, given DRG's contacts and greater familiarity with the mechanics of the policy-making process. In order to create a more even playing field it is important to understand other sector priorities, available resources, and modus operandi. Different sectors may have different sets of assumptions, theories of change or terminologies. In some LEP projects, however, they have become much more supportive after they saw that the project was yielding benefits, and awareness emerged that their programs could be aided by the inclusion of a legislative engagement element.

\subsection{Policy Community Concept}

An integral element of the legislative engagement approach is the formation and functioning of informed policy legislative communities. These are groupings of civil society associations, advocacy organizations, research institutes and/or other non-governmental sources with common interests that can articulate policy options and alternatives, develop shared goals and visons, serve as an information resource for the legislatures, and help strengthen citizens' engagement and input into policy development. This in turn can result in legislators engaging in more pro-active dialogue with constituents and stakeholders on a variety of specific development issues. This could also include additional and more regularized flow of information into the legislative process. Policy communities can potentially be expanded to include parliamentary caucuses or legislative staff. The creation of policy communities has flowed from a recognition that policy in lawmaking often occurs within executive branch ministries with insufficient input from policy experts, civil society, and ordinary citizens.

\subsection{Continued Focus on Executive Branch}

Most legislative initiatives emanate from the executive branch. It may well be that legislative engagement policy-oriented projects cannot be focused solely or specifically on legislative policy development but more holistically, on the policy formation process on the executive branch side as well as with the legislature. The extent to which cross-sectoral policy reform initiatives should be focused solely on the legislature or whether they should be oriented in a more holistic legislative and executive branch perspective obviously depends on circumstances, but it is a factor to be considered.

\section{Conclusions}

The inter-related nature of development challenges is receiving belated increased attention. On example of this has been understanding of and support for the role of legislatures in helping to promote developmental goals through setting priorities, exercising the power of the purse, authoring legislation, and focusing public opinion and attention on key issues. There has been a move in the direction of USAID programming to support activities to further integrated and broader developmental goals. This has occurred for substantive reasons, especially as there is increased recognition of the key role policy formulation plays in development, and of the need to involve legislatures in this complex and often non-linear process. This has also occurred because of resource constraints and a heightened focus on achieving multiple goals with targeted investments. USAID continues, in effect, to search for the "Holy Grail" of programming that can help to ensure that legislatures play their role in promoting economic development and democratic governance.

There are problems and challenges related to this approach; legislative engagement programming is not necessarily the be-all and end-all of legislative functioning. To date there is little, if any, empirical data demonstrating the general effectiveness of the approach. Decision making on policy issues does not always reflect political considerations, and often trumps informed policy choices. Legislatures can slow down the policy-making and implementation process. A paradox exists in that heightened legislative involvement can lead to delays and inefficiencies as legislators may review, alter, impede or otherwise slow things down. The bottom line is that in democracies, without legislative buy-in, policies risk being ephemeral as a range of stakeholders may not have had a say in the decision-making process and may thus not be supportive of the policy in question. LEP also requires active buy-in and cooperation between different developmental sectors. The legislature can be a tricky interlocutor, given limited capacities, member turn-over, at-times ambivalent or negative legislative leadership attitudes towards assistance, crowded and/or slow-moving legislative agendas and the vagaries of political considerations. The time frame required for impact to register may be longer than the lifespan of a typical assistance project. The need for policy dialogue with other sectors of government, especially the executive branch, can drain attention and resources away from the legislative side of the equation.

Despite these challenges the risks of ignoring the interface between legislative support and development could marginalize and isolate legislative support as a subject worthy of USAID focus, and negatively impact the 
attainment of developmental goals. The current emphasis towards integrated programming therefore undoubtedly does not represent "the end of history" in terms of legislative support programming. This is especially true given the lack of a significant sample of evaluations and assessments regarding outcomes linked to legislative engagement programming. Nonetheless, if the programming can be designed properly, legislative engagement activities have the potential to represent a judicious and cost-effective use of limited resources. They can serve to improve policy dialogue, promote development goals, improve the functioning of the legislature, and create "buy-in" on the part of key legislative personnel. They can also result in more effective communication and dialogue between the legislature and the executive branch, as well as dialogue with other stakeholders and sectors of society.

\section{REFERENCES}

[1] J.S. Rotberg and J. Salahub. African Legislative Effectiveness, The North-South Institute, Ottawa, 17, 2013.

[2] D. Arter. Introduction: Comparing the Legislative Performance of Legislatures, The Journal of Legislative Studies, 12:3-4, 245-257, 2007.

[3] E. Malesky, P. Schuler and A. Tran. The Adverse Effects of Sunshine: A Field Experiment on Legislative Transparency in an Authoritarian Assembly, American Political Science Review, 106:4, 762, 2012.

[4] M. Kroenig and M. Karan-Delhaye. Do Legislatures Matter for Economic Growth?, DAI, Inc., Washington DC, 8, 2011.

[5] K. Sharkey. The Role of Legislatures in Poverty Reduction: Experience and Future Directions, World Bank Institute, Washington, DC, 2006.

[6] A. Cornell. Does Regime Type Matter for the Impact of Democracy Aid on Democracy?, Democratization, 20:4, 642-667, 2013.

[7] J. D. Barkan, Legislative Power in Emerging African Democracies in African Legislatures and the "Third Wave" of Democratization, Lynne Rienner, Boulder, CO: 2010.

[8] S.M. Rugumamu. Capacity Development in Fragile Environments: Insights from Parliaments in Africa, World Journal of Entrepreneurship, Management and Sustainable Development, 7, 2011.

[9] J. Hibbing and S. Patterson. The U.S. Congress' Modest Influence on the Legislatures of Central and Eastern Europe", in T. Power and N. Rae, "Exporting Congress? The Influence of the U.S. Congress on the World's Legislatures", University of Pittsburgh Press, Pittsburgh, 13, 2006.

[10] J. Wedel. Collision and Collusion: The Case of Western Aid to Eastern Europe, Palgrave, New York, 80, 2001.

[11] S. Bryan, and B. Hofmann. Transparency and Accountability in Africa's Extractive Industries: The Role of the Legislature, National Democratic Institute for International Affairs. Washington, D.C., 28, 2007.
[12] J. D. Barkan, Legislative Power in Emerging African Democracies in African Legislatures and the "Third Wave" of Democratization, Lynne Rienner, Boulder, CO: 2010.

[13] D. Arter. Introduction: Comparing the Legislative Performance of Legislatures, The Journal of Legislative Studies, 12:3-4, 245-257, 2007.

[14] Inter-Parliamentary Union. Informing Democracy: Building Capacity to Meet Parliamentarians' Information and Knowledge Needs, Report No. 59, Geneva, 17, 2008.

[15] A. Datta and N. Jones. Linkages Between Researchers and Legislators in Developing Countries, Working Paper 332, Overseas Development Institute, London. 17, 2011.

[16] K. Cuninghame. Guidelines for Legislative Libraries, 140(2), The International Federation of Library Associations and Institutions, Germany, 2009.

[17] D. Dreier. House Democracy Partnership, United States House of Representatives, Washington, DC, 14, 2012.

[18] Inter-Parliamentary Union. Informing Democracy: Building Capacity to Meet Parliamentarians' Information and Knowledge Needs, Report No. 59, Geneva, 7, 2008.

[19] M. Andrews and L. Bategeka. Overcoming the Limits of Institutional Reform in Uganda, United Nations University-World Institute for Development Economics Research, Center for International Development, Harvard University, CID Working Paper No. 269, 21, 2013.

[20] C. Roth. Helping Parliaments and Legislative Assemblies to Work for the Poor. Policy Division, Department for International Development, DFID, London, 48, 2004.

[21] R. Purcell, C. Dom, and G. Ahobamuteze. Evaluation of General Budget Support--Rwanda Country Report: A Joint Evaluation of General Budget Support 1994-2004, International Development Department, School of Public Policy, University of Birmingham, Birmingham, UK, 2006.

[22] J. Wehner. Back from the Sidelines? Redefining the Contribution of Legislatures to the Budget Cycle, World Bank Institute, Washington, 2004.

[23] K. McKie, and N. van de Walle. Toward an Accountable Budget Process in Sub-Saharan Africa: Problems and Prospects, From Impunity to Accountability: Africa's Development in the 21st Century, 77(4), 1283, 2010.

[24] J.K. Johnson and R. Stapenhurst. Legislative Budget Offices: International Experience - Legislative Oversight and Budgeting, World Bank Institute Development Studies, 2008.

[25] A. Staddon. "Strengthening PACs in Small Parliaments: Perspectives from the Caribbean" in Z. Hoque (ed), Making Governments Accountable: The Role of Public Accounts Committees and National Audit Office, Routledge, London, 2014.

[26] T. Carothers. Aiding Democracy Abroad: The Learning Curve, The Carnegie Endowment, Washington, DC, 182, 1999.

[27] US Agency for International Development. Evaluation of the Indiana University Parliamentary Development Program, Washington, DC, 2008.

[28] US Agency for International Development. Audit of USAID/Jordan's Democracy and Governance Activities, Audit Report \# 6-278-09-001-P October 28, 2008, USAID Office of the Inspector General, Washington, DC, 2008. 
[29] T. Carothers. Aiding Democracy Abroad: The Learning Curve, The Carnegie Endowment, Washington, D.C. 183, 1999.

[30] US Agency for International Development. Final Evaluation of USAID's Office of Transition Initiatives in Peru, Washington, DC, 16, 2003.

[31] US Agency for International Development. Evaluation of the Support for Electoral Processes, Political Party Development and Legislative Strengthening Project, Washington, DC, 28, 2003.

[32] The Mitchell Group. An Evaluation of the National Democratic Institute (NDI) Legislative Strengthening Program in Liberia, Washington, DC., 2, 2013.

[33] US Agency for International Development. Iraq Monitoring and Evaluation Performance Program: Final Report for Political Process Assistance and Review, Washington, DC, 3, 2005.

[34] R. Stapenhurst, Helping Parliaments to Help the Poor. Public Sector Reform and Capacity Building, World Bank, Washington, DC, 2003.

[35] H. Lippman. Linking Democracy and Development: An Idea for the Times, USAID Program and Operations Assessment Report: U.S. Agency for International Development, Washington DC, 2001.

[36] C. Roth. Helping Parliaments and Legislative Assemblies to Work for the Poor, Policy Division, Department for International Development, DFID, London, 48, 2004.

[37] United Nations Development Program. Parliamentary Engagement Development with the Millennium Goals, New York, 2010.

[38] C. Kroon and R. Stapenhurst. Parliament's Role in Poverty Reduction Strategies, World Bank Institute, Washington, DC, 26, 1, 2008.
[39] K. Sharkey, T. Dreger and S. Bhatia. The Role of Legislatures in Poverty Reduction: Experience and Future Directions, World Bank Institute Working Paper 38925, Washington, DC, 2006.

[40] M. Kroenig and M. Karan-Delhaye. Do Legislatures Matter for Economic Growth?, DAI, Inc., Washington DC, 1, 2011.

[41] H. Lippman. Linking Democracy and Development: An Idea for the Times, USAID Program and Operations Assessment Report: U.S. Agency for International Development, Washington DC, 2001 .

[42] H. Lippman. Linking Democracy and Development: An Idea for the Times, USAID Program and Operations Assessment Report: U.S. Agency for International Development, Washington DC, 20, 2001.

[43] S. Bryan, and B. Hofmann. Transparency and Accountability in Africa's Extractive Industries: The Role of the Legislature, National Democratic Institute for International Affairs. Washington, D.C., 28, 2007.

[44] J. Kaufman and B. Smith. USAID Strategy on Democracy Human Rights and Governance: US Agency for International Development, Washington DC, 2013.

[45] US Agency for International Development. The Fourth Report on the Implementation of USAID Disability Policy, Washington, DC, 25, 2005.

[46] The Mitchell Group, Inc. Evaluation of Niger CEPPS Niger Increasing Transparency and Accountability in the Management of Natural Resources Program, Washington, DC, V, 2014.

[47] The Mitchell Group, Inc. Evaluation of Niger CEPPS Niger Increasing Transparency and Accountability in the Management of Natural Resources Program, Washington, DC, 23,2014

[48] T. Carothers. Aiding Democracy Abroad: The Learning Curve, The Carnegie Endowment, Washington, D.C. 182, 1999. 